\title{
Non-classical hereditary hemochromatosis in Portugal: novel mutations identified in iron metabolism-related genes
}

\author{
Ana Isabel Mendes • Ana Ferro • Rute Martins • \\ Isabel Picanço • Susana Gomes • Rute Cerqueira • \\ Manuel Correia • António Robalo Nunes • \\ Jorge Esteves • Rita Fleming $\cdot$ Paula Faustino
}

Received: 12 June 2008 / Accepted: 21 July 2008 / Published online: 2 September 2008

(C) Springer-Verlag 2008

\begin{abstract}
The most frequent genotype associated with Hereditary hemochromatosis is the homozygosity for C282Y, a common HFE mutation. However, other mutations in $H F E$, transferrin receptor 2 (TFR2), hemojuvelin (HJV) and hepcidin $(H A M P)$ genes, have also been reported in association with this pathology. A mutational analysis of these genes was carried out in 215 Portuguese iron-overloaded individuals previously characterized as non-C282Y or non-H63D homozygous and non-compound heterozygous. The aim was to determine the influence of these genes in the development of iron overload phenotypes in our population. Regarding
\end{abstract}

\footnotetext{
A. I. Mendes · A. Ferro • R. Martins • I. Picanço • S. Gomes •

P. Faustino

Human Genetics Centre,

National Institute of Health Dr. Ricardo Jorge,

Lisbon, Portugal

R. Cerqueira $\cdot$ M. Correia

Service of Gastroenterology, Santa Maria da Feira Hospital, Santa Maria da Feira, Portugal
}

\author{
A. R. Nunes \\ Service of Immuno-hemotherapy, Pulido Valente Hospital, \\ Lisbon, Portugal \\ J. Esteves \\ Unit of Gastroenterology, S. José Hospital, \\ Lisbon, Portugal \\ R. Fleming \\ Service of Immuno-hemotherapy, Santa Maria Hospital, \\ Lisbon, Portugal \\ P. Faustino $(\square)$ \\ Centro de Genética Humana, \\ Instituto Nacional de Saúde Dr. Ricardo Jorge, \\ Avenida Padre Cruz, \\ 1649-016 Lisbon, Portugal \\ e-mail: paula.faustino@insa.min-saude.pt
}

HFE, some known mutations were found, as $\mathrm{S} 65 \mathrm{C}$ and E277K. In addition, three novel missense mutations (L46W, D129N and Y230F) and one nonsense mutation (Y138X) were identified. In TFR2, besides the I238M polymorphism and the rare IVS5 $-9 \mathrm{~T} \rightarrow \mathrm{A}$ mutation, a novel missense mutation was detected (F280L). Concerning HAMP, the deleterious mutation 5'UTR $-25 \mathrm{G} \rightarrow \mathrm{A}$ was found once, associated with Juvenile Hemochromatosis. In HJV, the A $310 \mathrm{G}$ polymorphism, the novel E275E silent alteration and the novel putative splicing mutation (IVS2 $+395 \mathrm{C} \rightarrow \mathrm{G}$ ) were identified. In conclusion, only a few number of mutations which can be linked to iron overload was found, revealing their modest contribution for the development of this phenotype in our population, and suggesting that their screening in routine diagnosis is not cost-effective.

Keywords Hereditary hemochromatosis · HFE non-C282Y Population screening

\section{Introduction}

Hereditary hemochromatosis $(\mathrm{HH})$ is an autosomal recessive disorder of adult-onset, common among Caucasians of Northern European ancestry, which leads to iron overload in several organs, if left untreated. Molecular studies have shown that $\mathrm{HH}$ is prevalently due to a founder missense mutation, $\mathrm{C} 282 \mathrm{Y}$, in the HFE gene on chromosome 6p21.3 [1]. Although $\mathrm{C} 282 \mathrm{Y}$ in the homozygous condition remains the most frequent patients' genotype, other $H F E$ mutations such as H63D and $\mathrm{S} 65 \mathrm{C}$ have been described in compound heterozygosity with C282Y [1, 2]. In Southern Europe, a large percentage of individuals (35-45\%) with HH phenotypes are neither $\mathrm{C} 282 \mathrm{Y}$ homozygous nor C282Y/H63D compound heterozygous. Other very rare or private $H F E$ variants have 
been reported in affected individuals, contributing to the $\mathrm{HH}$ genetic heterogeneity [3-10]. Moreover, an association of $\mathrm{HH}$ with other genes, such as the transferrin receptor 2 (TFR2) [11-16], the hemojuvelin (HJV) [17-25] and the hepcidin (HAMP) [14, 26-31] genes, has also been documented. These latter two genes are mainly associated with the juvenile form of the disease (Juvenile Hemochromatosis, $\mathrm{JH})$. The purpose of the current study was to search for uncommon HFE, TFR2, HJV, or HAMP mutations liable to explain the iron overload phenotype in Portuguese individuals previously characterized as non-C282Y or non-H63D homozygous and non-compound heterozygous. The result of this study will allow clarifying the importance of these genes in the routine HH genetic diagnosis in the Portuguese population.

\section{Materials and methods}

\section{Selection of participants}

The studied population consisted of 215 patients referred to the Human Genetics Centre of the National Institute of Health Dr. Ricardo Jorge in Lisbon, Portugal, for HH genetic testing. The criteria for patient's inclusion were to be adult, not related and presenting serum ferritin level $>400 \mathrm{ng} / \mathrm{ml}$ or transferrin saturation $>50 \%$ (unless currently treated by phlebotomy). All these patients were previously diagnosed as non-C282Y or non-H63D homozygous and non-compound heterozygous.

Fifty control samples from unrelated healthy individuals were also studied. Investigations were undertaken with the written informed consent of all participants.

\section{Molecular studies}

Polymerase chain reaction (PCR) amplification of HFE exons 2, 3 and 4, and of TFR2 exons 2, 4, 5 and 6 (including intron/exon boundaries) was performed for each patient's DNA, as described by Le Gac et al. 2001 [7] and Roetto et al. 2001 [12]. Screening for mutations in PCR-amplified DNA was performed by using both single-strand conformation polymorphism (SSCP) and denaturing high performance liquid chromatography (dHPLC). Purified PCR products presenting altered profiles were directly sequenced using the ABI Prism BigDye Terminator v1.1 Cycle Sequencing Kit in the ABI Prism 3130xl Genetic Analyzer (Applied Biosystems). Codifying regions of $H J V$ and HAMP genes were screened by dHPLC as described or were directly sequenced $[18,19,27,29]$.

In silico studies

Potential splice signals of mutated DNA sequences were analyzed using the SpliceView software (http://125.itba.mi. cnr.it/ webgene/wwwspliceview.html) and multiple sequence alignment of HFE protein from mouse, rat, human and dog was accomplished by using the ClustalW $v 1.82$ software (http://www.ebi.ac.uk/clustalw).

\section{Results and discussion}

In this study, the mutational screening of $H F E$ and TFR2 was performed by using two different methodologies, SSCP and dHPLC. The analysis of HFE exon 2 revealed five abnormal profiles. The respective sequencing allowed the identification of the known S65C in compound heterozygosity with H63D in two individuals, in compound heterozygosity with $\mathrm{C} 282 \mathrm{Y}$ in other individual, and in another one in the heterozygous condition. The other abnormal profile was due to a $T \rightarrow G$ transversion in heterozygosity at codon 46 (Fig. 1a). Consequently, leucine is replaced by tryptophan originating a novel mutation, L46W. It was found in a 45 -year-old male presenting a transferrin saturation $=68 \%$ and ferritin $=444 \mathrm{ng} / \mathrm{ml}$.

Although three abnormal dHPLC profiles of HFE exon 3 were observed, only two of them were detected by SSCP. One was due to a $\mathrm{G} \rightarrow \mathrm{A}$ transition at codon 129 (Fig. 1b), resulting in an aspartic acid to asparagine alteration and, consequently to the novel D129N mutation. It was detected in a 35-year-old man in compound heterozygosity with H63D. The patient presented transferrin saturation $=79.6 \%$ and ferritin $=135 \mathrm{ng} / \mathrm{ml}$.

Both L46W and D129N patients' families were not available to be studied, so it was not possible to observe a familiar segregation associated to the iron overload phenotype. The L46W mutation is localized near the flexible HFE $\alpha 1$ domain loop Q40-S45, which interacts with helix 1 of the transferrin receptor 1 (TfR1) helical domain $[32,33]$. On the other hand, the D129N mutation modifies a residue located in HFE $\alpha 2$ domain which interacts with helix 2 of TfR1. Therefore, these two novel mutations could affect HFE affinity for TfR1 and consequently might interfere with its proper functioning. Moreover, it was observed that both L46 and D129 are highly conserved residues (Fig. 2a and b), so they should be important for protein function. Splicing analysis suggested that both mutations do not affect splicing.

As L46W was found only in heterozygosity, it is unlikely that this mutation, by itself, justifies the patient iron overload. In addition, this individual has alcoholic habits that probably also contribute to his iron burden. Concerning the D129N/ H63D patient, attending to the novel mutation putative functional effects and to the absence of known external contributor factors, it might be a pathologic genotype.

Sequencing of the other two HFE exon 3 abnormal profiles revealed two novel alterations at tyrosine 138: $\mathrm{C} \rightarrow \mathrm{T}$ and $\mathrm{C} \rightarrow \mathrm{G}$, giving rise to Y138Y (only detected by dHPLC) and Y138X, respectively. The former alteration that does not change the amino acid, was detected in heterozygosity in a 
Fig. 1 Sequencing results showing the mutations found in the HFE, TFR2 and HJV genes
A. HFE L46W

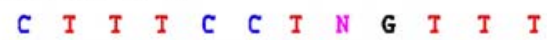

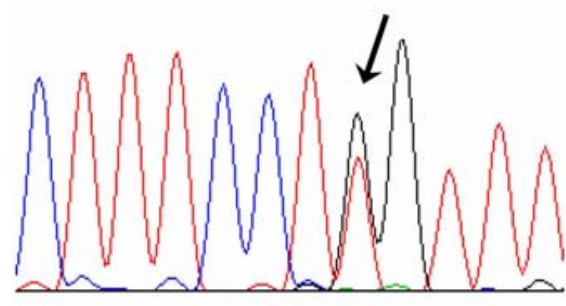

C. HFE Y $138 \mathrm{X}$

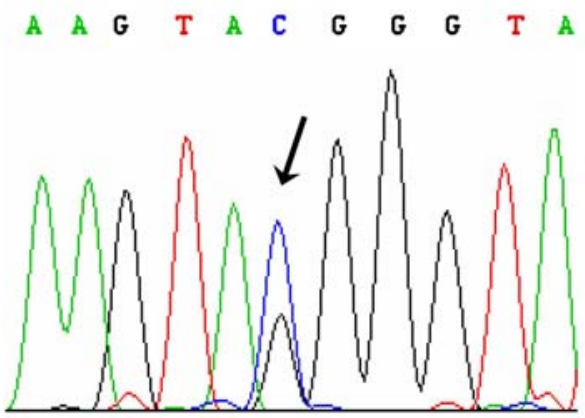

E. TFR2 $\mathrm{F} 280 \mathrm{~L}$

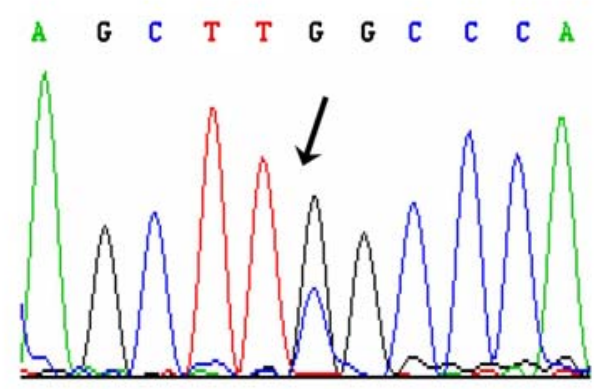

B. $H F E \mathrm{D} 129 \mathrm{~N}$
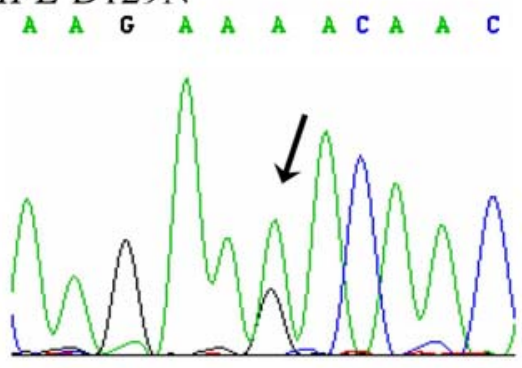

D. $H F E \mathrm{Y} 230 \mathrm{~F}$

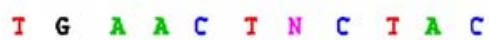

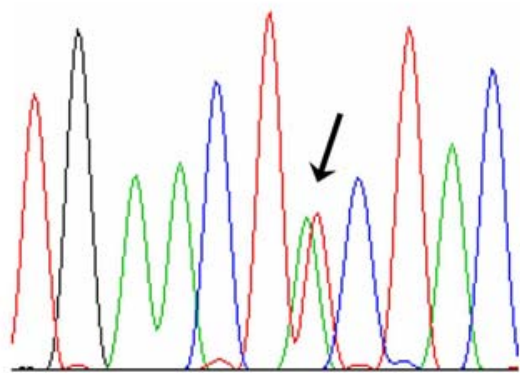

F. $H J V$ IVS $2+395 \mathrm{C} \rightarrow \mathrm{G} \quad$ Exon 3 C T G T G T T TA $\quad$ G $\underset{\text { C }}{\longrightarrow}$

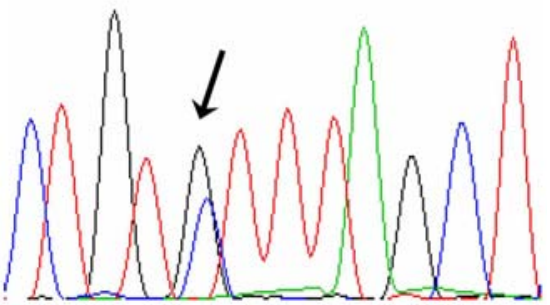

\section{A. HFE L46W}

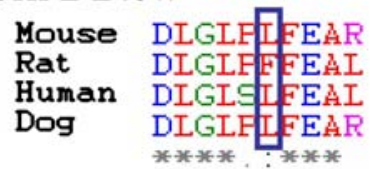

C. $H F E \mathrm{Y} 230 \mathrm{~F}$

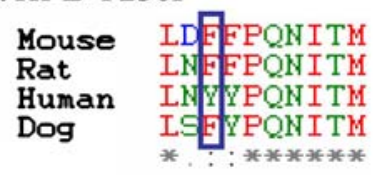

E. TFR2 F280L

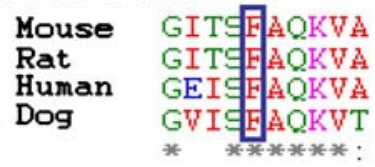

Fig. 2 Multiple sequence alignment of HFE and TFR2 protein from mouse, rat, human and dog using the ClustalW v1.82 software. Considered residues are indicated by a rectangle; identical residues by an asterisk $(*)$; conserved substitutions by a colon (:) and semiconserved substitutions by a dot (.)

B. $H F E \mathrm{D} 129 \mathrm{~N}$
Mouse EVHERNSTSG

Rat EVHELNSTSG

Human EMOFLHSTEG

Dog EVQELISTTG

D. $H F E \mathrm{E} 277 \mathrm{~K}$

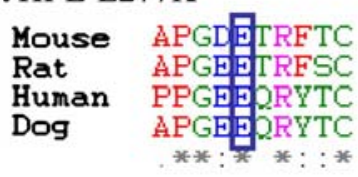

69-year-old man who presents transferrin saturation $=45 \%$ and ferritin $=1466 \mathrm{ng} / \mathrm{ml}$. This mutation causes a minor alteration of the consensus value of a potential donor site (from 82 to 79). However, because this site is not commonly used, it is unlikely that this mutation affects splicing. So it may be an alteration without any pathologic significance and does not justify the patient's iron overload.

On the opposite, the nonsense mutation (Y138X) (Fig. 1c) was detected in compound heterozygosity with $\mathrm{C} 282 \mathrm{Y}$ in a 63 -year-old man presenting transferrin saturation $=90 \%$ and ferritin $=1,000 \mathrm{ng} / \mathrm{ml}$. This novel mutation originates a premature stop codon and consequently the correspondent mRNA will be committed to the nonsense-mediated mRNA decay mechanism. Therefore, this patient genotype (Y138X/ C282Y) entirely justifies his HH phenotype.

Two altered $H F E$ exon 4 profiles were found. Sequencing revealed in one case a novel heterozygous $\mathrm{A} \rightarrow \mathrm{T}$ transversion at codon 230 (Fig. 1d), substituting a tyrosine for a phenylalanine (Y230F). The patient's family study revealed that 
although his father is a compound heterozygous for $\mathrm{Y} 230 \mathrm{~F}$ and $\mathrm{H} 63 \mathrm{D}$, he presents normal iron parameters (Table 1). Y230F alters a residue positioned on a $\beta$-strand of the $\alpha 3$ domain which binds to $\beta 2$-microglobulin $[32,33]$. However, the Y230 position is originally occupied by a phenylalanine in some species (Fig. 2c), suggesting that tyrosine at position 230 may not be essential. Also, this mutation induces a small alteration of a potential acceptor site consensus value (from 81 to 85 ) but probably without consequences. Taking into consideration all these facts, it is unlikely that this mutation is contributing for the iron overload in this patient.

The other abnormal profile found in HFE exon 4 was due to the known E277K $[34,35]$ mutation, found in compound heterozygosity with H63D in a patient. His family study showed that his brother presents the same genotype and also a high serum ferritin level (Table 2). The mutation does not alter splicing signals and E277 is highly conserved between species (Fig. 2d). Although the E277K has been previously described as a neutral polymorphism [34], in this study, it was detected in compound heterozygosity with H63D in two brothers both presenting altered iron parameters. Due to its HFE $\alpha 3$ domain localization, this amino acid alteration might perturb the binding to $\beta 2$-microglobulin, affecting HFE correct processing. Altogether these facts suggest some deleterious effect of this mutation, but only functional studies could determine its real significance.

The screening of TFR 2 revealed that three out of the 215 patients had altered dHPLC profiles. The direct sequencing identified one heterozygous transversion $\mathrm{C} \rightarrow \mathrm{G}$ at codon 238, which causes an amino acid substitution from isoleucine to methionine, I238M. This alteration was already reported as a polymorphism by Lee et al, 2001 [13].

Another TFR2 variant corresponds to a novel $\mathrm{C} \rightarrow \mathrm{G}$ mutation at codon 280 (Fig. 1e) which originates a phenylalanine to leucine substitution (F280L). It was found in double heterozygosity with H63D in a 29 -year-old man presenting a transferrin saturation $=80 \%$ and ferritin $=111 \mathrm{ng} / \mathrm{ml}$. This mutation does not alter splicing signals and F280 is a highly conserved residue (Fig. 2e). It is located in the apical

Table 1 Clinical data of the $H F E$ Y230F family

\begin{tabular}{lllll}
\hline & Propositus & Father & Mother & Brother \\
\hline Age (years) & 30 & 55 & 54 & 23 \\
Sex & $\mathrm{M}$ & $\mathrm{M}$ & $\mathrm{F}$ & $\mathrm{M}$ \\
Cardiomyopathy & - & + & - & - \\
Diabetes mellitus & - & - & + & - \\
Iron $(\mu \mathrm{g} / \mathrm{dl})$ & 162 & 76 & 69 & 63 \\
Transferrin & 75.8 & 35.8 & 26.3 & 32.1 \\
$\quad$ saturation (\%) & & & & \\
Ferritin (ng/ml) & 531 & 165 & 74 & 258 \\
HFE genotype & Y230F/wt & Y230F/H63D & $\mathrm{wt} / \mathrm{wt}$ & $\mathrm{H} 63 \mathrm{D} / \mathrm{wt}$ \\
\hline
\end{tabular}

$w t$ Wild type, + presence, - absence
Table 2 Clinical data of the HFE E277K family

\begin{tabular}{lllll}
\hline & Propositus & Brother & Sister I & Sister II \\
\hline Age (years) & 63 & 67 & 59 & 46 \\
Sex & $\mathrm{M}$ & $\mathrm{M}$ & $\mathrm{F}$ & $\mathrm{F}$ \\
Cardiomyopathy & - & + & - & - \\
Iron $(\mu \mathrm{g} / \mathrm{dl})$ & 185 & 115 & 77 & 30 \\
Transferrin & 60.7 & 39.5 & 25 & 9 \\
$\begin{array}{l}\text { saturation (\%) } \\
\text { Ferritin }(\mathrm{ng} / \mathrm{ml})\end{array}$ & 620 & 812 & 72 & 20.8 \\
$H F E$ genotype & E277K/H63D & E277K/H63D & $\mathrm{H} 63 \mathrm{D} / \mathrm{wt}$ & $\mathrm{wt} / \mathrm{wt}$ \\
\hline
\end{tabular}

$w t$ Wild type, + presence, - absence

region of TFR2, so the amino acid change might perturb protein function and, consequently, it's binding to transferrin. Considering the patient's alcoholic habits, the cause of his iron overload is probably the combined action of genetic and environmental factors. The F280L mutation requires functional studies to complete its characterization.

The other TFR2 abnormal profile found corresponded to the rare IVS5 $-9 \mathrm{~T} \rightarrow \mathrm{A}$ alteration [15]. It was detected in double heterozygosity with H63D in a 38-year-old man presenting transferrin saturation $=51 \%$ and ferritin $=186 \mathrm{ng} / \mathrm{ml}$. This mutation produces a small reduction of the native acceptor splicing site consensus value ( 88 to 84 ) and its effect on splicing can be hypothesized.

The $5^{\prime} \mathrm{UTR}-25 \mathrm{G} \rightarrow \mathrm{A}$ (24) mutation was found in homozygosity in the HAMP gene in a 50-year-old man who presented, at the age of 28 , a severe juvenile hemochromatosis phenotype (transferrin saturation $=70 \%$; cardiomyopathy, hepatomegaly, intense hepatic hemosiderosis) [36]. This mutation creates a new initiation codon at position +14 related to the cap site, which induces a shift of the open reading frame. Homozygosity for this mutation was previously reported as the cause of $\mathrm{JH}$ in two other individuals of Portuguese origin [31,37]. As this third affected individual had a birth place located near the first one described (Matthes T, personal communication), probably they are related to the same HAMP mutational event.

Two of the $H J V$ alterations found are apparently asymptomatic. The $\mathrm{A} 310 \mathrm{G}$ is described as a polymorphism in ensEMBL (www.ensembl.org) and GeneCards ${ }^{\circledR}$ (www. genecards.org) databases. The other one, a $\mathrm{G} \rightarrow \mathrm{A}$ transition at codon 275, does not alter the amino acid residue (E275E) and does not seem to affect splicing. On the other hand, the third alteration observed, the IVS2 $+395 \mathrm{C} \rightarrow \mathrm{G}$ (Fig. 1f), was detected in heterozygosity in a 29 -year-old man presenting transferrin saturation $=59 \%$ and ferritin $=661 \mathrm{ng} / \mathrm{ml}$. It is located at six deoxyribonucleotides from the beginning of exon 3 and induces an alteration of the consensus value of the native acceptor site (from 89 to 85), which becomes lower than another potential splice site (86). Consequently, some competition between these two splice sites might 
occur, altering the splicing variants produced. Even if the mutation deleterious effect is confirmed in future functional studies, it is improbable that its heterozygosity is the only cause of the individual iron overload.

All novel mutations found were searched for and not found in 50 healthy individuals, so they cannot be considered polymorphisms.

In conclusion, in this study, several alterations were found in HFE, TFR2, HJV, and HAMP genes, screened in 215 Portuguese individuals presenting iron overload, previously characterized as non-C282Y or non-H63D homozygous or compound heterozygous. However, only a few number of these mutations can be directly associated with $\mathrm{HH}$ or $\mathrm{JH}$, revealing a modest contribution of the novel variants in this phenotype development, and suggesting that their screening in routine diagnosis is not cost-effective. Nevertheless, the identification and study of these novel mutations is important to enlarge the knowledge of the HH genetic heterogeneity. Additionally, their functional study can be significant for a better understanding of the correspondent proteins role in the iron metabolism and in $\mathrm{HH}$ development.

Acknowledgements We thank G. Le Gac (Establissement Français du Sang-Bretagne, Brest, France), G. Biasiotto (Università di Brescia, Italy), F. Daraio (Università di Torino, Italy) e A. Roetto (Università di Torino, Italy) for having kindly supplied mutant controls. We also thank the Unidade Laboratorial de Utilização Comum of the National Institute of Health Dr. Ricardo Jorge for technical support.

This work was partially supported by Fundação para a Ciência e a Tecnologia, Programa de Financiamento Plurianual do CIGMH. This work was awarded by Comissão de Fomento da Investigação em Cuidados de Saúde, Ministério da Saúde P.I. no. 130/2007.

\section{References}

1. Feder JN, Gnirke A, Thomas W, Tsuchihashi Z, Ruddy DA, Basava A et al (1996) A novel MHC class I-like gene is mutated in patients with hereditary haemochromatosis. Nat Genet 13:399408 doi:10.1038/ng0896-399

2. Mura C, Raguenes O, Ferec C (1999) HFE mutations analysis in 711 hemochromatosis probands: Evidence for S65C implication in mild form of hemochromatosis. Blood 93:2502-2505

3. Piperno A, Sampietro M, Pietrangelo A, Arosio C, Lupica L, Montosi $\mathrm{G}$ et al (1998) Heterogeneity of hemochromatosis in Italy. Gastroenterology 114:996-1002 doi:10.1016/S0016-5085(98)70319-1

4. de Villiers JN, Hillermann R, Loubser L, Kotze MJ (1999) Spectrum of mutations in the HFE gene implicated in haemochomatosis and porphyria. Hum Mol Genet 8:1517-1522 doi:10.1093/hmg/8.8.1517

5. Piperno A, Arosio C, Fossati L, Vigano M, Trombini P, Vergani A et al (2000) Two novel nonsense mutations of HFE gene in five unrelated Italian patients with hemochromatosis. Gastroenterology 119:441-445 doi:10.1053/gast.2000.9369

6. Pointon JJ, Wallace D, Merryweather-Clarke AT, Robson KJ (2000) Uncommon mutations and polymorphisms in the hemochromatosis gene. Genet Test 4:151-161 doi:10.1089/10906570050114867

7. Le Gac G, Mura C, Ferec C (2001) Complete scanning of the hereditary hemochromatosis gene (HFE) by use of Denaturing HPLC. Clin Chem 47:1633-1640
8. Beutler E, Griffin MJ, Gelbart T, West C (2002) A previously undescribed nonsense mutation of the $H F E$ gene. Clin Genet 61:40-42 doi:10.1034/j.1399-0004.2002.610108.x

9. Swinkels DW, Venselaar H, Wiegerinck ET, Bakker E, Joosten I, Jaspers CAJJ (2007) A novel (Leu183Pro) mutation in the HFEgene co-inherited with the Cys282Tyr mutation in two unrelated Dutch hemochromatosis patients. Blood Cells Mol Dis 40:334338 doi:10.1016/j.bcmd.2007.10.003

10. Dupradeau FY, Pissard S, Coulhon MP, Cadet E, Foulon K, Fourcade C (2007) An unusual case of hemochromatosis due to a new compound heterozygosity in HFE (p.[Gly43Asp; His63Asp] $+[$ Cys282Tyr]): structural implications with respect to binding with transferrin receptor 1. Hum Mutat 29:206-213 doi:10.1002/ humu. 9517

11. Camaschella C, Roetto A, Cali A, De Gobbi M, Garozzo G, Carella $\mathrm{M}$ et al (2000) The gene encoding transferrin receptor 2 is mutated in a new type of hemochromatosis mapping to $7 \mathrm{q} 22$. Nat Genet 25:14-15 doi:10.1038/75534

12. Roetto A, Totaro A, Piperno A, Piga A, Longo F, Garozzo G et al (2001) New mutations inactivating transferrin receptor 2 in hemochromatosis type 3. Blood 97:2555-2560 doi:10.1182/blood.V97. 9.2555

13. Lee PL, Halloran C, West C, Beutler E (2001) Mutation analysis of the transferrin receptor-2 gene in patients with iron overload. Blood Cells Mol Dis 27:285-289 doi:10.1006/bcmd.2001.0381

14. Biasiotto G, Belloli S, Ruggeri G, Zanella I, Gerardi G, Corrado M et al (2003) Identification of new mutations of the HFE, hepcidin, and transferrin receptor 2 genes by denaturing HPLC analysis of individuals with biochemical indications of iron overload. Clin Chem 49:1981-1988 doi:10.1373/clinchem.2003.023440

15. Mattman A, Huntsman D, Lockitch G, Langlois S, Buskard N, Ralston D et al (2002) Transferrin receptor 2 (TfR2) and HFE mutational analysis in non-C282Y iron overload: identification of a novel TfR2 mutation. Blood 100:1075-1077 doi:10.1182/blood2002-01-0133

16. Gérolami V, Le Gac G, Mercier L, Nezri M, Bérgé-Lefranc LB, Férec C (2008) Early-haemochromatosis caused by a novel combination of TFR2 mutations (p.R396X/c.1538-2 A>G) in a woman of Italian descent onset. Haematologica 93:e45-e46 doi:10. 3324/haematol.12884

17. Papanikolaou G, Samuels ME, Ludwig EH, MacDonald ML, Franchini PL, Dube MP et al (2004) Mutations in HFE2 cause iron overload in chromosome 1q-linked juvenile hemochromatosis. Nat Genet 36:77-82 doi:10.1038/ng1274

18. Le Gac G, Scotet V, Ka C, Gouraouen I, Bryckaert L, Jacolot S et al (2004) The recently identified type 2 A juvenile haemochromatosis gene $(H J V)$, a second candidate modifier of the $\mathrm{C} 282 \mathrm{Y}$ homozygous phenotype. Hum Mol Genet 13:1913-1918 doi:10.1093/hmg/ ddh206

19. Lanzara C, Roetto A, Daraio F, Rivard S, Ficarella R, Simard H et al (2004) Spectrum of hemojuvelin gene mutations in 1q-linked juvenile hemochromatosis. Blood 103:4317-4321 doi:10.1182/ blood-2004-01-0192

20. Lee PL, Beutler E, Rao SV, Barton JC (2004) Genetic abnormalities and juvenile hemochromatosis: mutations of the HJV gene encoding hemojuvelin. Blood 103:4669-4671 doi:10.1182/blood2004-01-0072

21. Huang FW, Rubio-Aliaga I, Kushner JP, Andrews NC, Fleming MD (2004) Identification of a novel mutation (C321X) in HJV. Blood 104:2176-2177 doi:10.1182/blood-2004-01-0400

22. van Dijk BA, Kemna EH, Tjalsma H, Klaver SM, Wiegerinck ET, Goossens JP (2007) Effect of the new HJV-L165X mutation on penetrance of HFE. Blood 109:5525-5526 doi:10.1182/blood2006-11-058560

23. Ka C, Le Gac G, Letocart I, Martin B, Férec C (2007) Phenotypic and functional data confirm causality of the recently identified hemoju- 
velin p.r176c missense mutation. Haematologica 92:1262-1263 doi:10.3324/haematol.11247

24. de Diego C, Opazo S, Sánchez-Castaño A, Martínez-Castro P (2007) New HJV mutation in a patient with hyperferritinemia and H63D homozygosity for the HFE gene. Int J Hematol 86:379-380 doi:10.1532/IJH97.E0748

25. Aguilar-Martinez P, Loc CY, Cunat S, Cadet E, Robson K, Rochette J (2007) Juvenile hemochromatosis caused by a novel combination of hemojuvelin G320V/R176C mutation in a 5-year old girl. Haematologica 92:421-422 doi:10.3324/haematol.10701

26. Roetto A, Papanikolaou G, Politou M, Alberti F, Girelli D, Christakis J et al (2003) Mutant antimicrobial peptide hepcidin is associated with severe juvenile hemochromatosis. Nat Genet 33:21-22 doi:10.1038/ng1053

27. Merryweather-Clarke AT, Cadet E, Bomford A, Capron D, Viprakasit V, Miller A et al (2003) Digenic inheritance of mutations in HAMP and HFE results in different types of haemochromatosis. Hum Mol Genet 12:2241-2247 doi:10.1093/hmg/ddg225

28. Delatycki MB, Allen KJ, Gow P, MacFarlane J, Radomski C, Thompson $\mathrm{J}$ et al (2004) A homozygous HAMP mutation in a multiply consanguineous family with pseudo-dominant hemochromatosis. Clin Genet 65:378-383 doi:10.1111/j.00099163.2004.00254.x

29. Jacolot S, Le Gac G, Scotet V, Quere I, Mura C, Ferec C (2004) $H A M P$ as a modifier gene that increases the phenotypic expression of the HFE pC282Y homozygous genotype. Blood 103:2835-2840 doi:10.1182/blood-2003-10-3366

30. Roetto A, Daraio F, Porporato P, Caruso R, Cox TM, Cazzola M et al (2004) Screening hepcidin for mutations in juvenile hemochromatosis: identification of a new mutation (C70R). Blood 103:2407-2409 doi:10.1182/blood-2003-10-3390

31. Matthes T, Aguilar-Martinez P, Pizzi-Bosman L, Darbellay R, RubbiaBrandt L, Giostra E et al (2004) Severe hemochromatosis in a Portuguese family associated with a new mutation in the $5^{\prime}$-UTR of the HAMP gene. Blood 104:2181-2183 doi:10.1182/blood-2004-01-0332

32. Lebron JA, Bennett MJ, Vaughn DE, Chirino AJ, Snow PM, Mintier GA et al (1998) Crystal structure of the hemochromatosis protein HFE and characterization of its interaction with transferrin receptor. Cell 93:111-123 doi:10.1016/S0092-8674(00)81151-4

33. Bennett MJ, Lebron JA, Bjorkman PJ (2000) Crystal structure of the hereditary haemochromatosis protein HFE complexed with transferrin receptor. Nature 403:46-53 doi:10.1038/47417

34. Bradbury R, Fagan E, Payne SJ (2000) Two novel polymorphisms (E277K and V212V) in the haemochromatosis gene HFE. Hum Mutat 15:120 doi:10.1002/(SICI)1098-1004(200001)15:1<120:: AID-HUMU32>3.0.CO;2-B

35. Karimi M, Yavarian M, Delbini P, Hartevweld CL, Farjadian S, Fiorelli $\mathrm{G}$ et al (2004) Spectrum and haplotypes of the HFE hemochromatosis gene in Iran: H63D in beta-thalassemia major and the first E277K homozygous. Hematol J 5:524-527 doi:10.1038/sj.thj.6200553

36. Pais de Lacerda A, Rocha E, Reis JM, Dionísio I, Lisboa P, Madeira H (1990) Hemocromatose cardíaca: uma "miocardia" curável. Rer Port Clin Terap 12:75-85

37. Porto G, Roetto A, Daraio F, Pinto JP, Almeida S, Bacelar C et al (2005) A Portuguese patient homozygous for the $-25 \mathrm{G}>\mathrm{A}$ mutation of the HAMP promoter shows evidence of steady-state transcription but fails to up-regulate hepcidin levels by iron. Blood 106:29222923 doi:10.1182/blood-2005-04-1630 